\title{
MAQUIAVELO: GEOMETRÍA DE LA REPÚBLICA
}

Roberto García Jurado*

\section{El estudio y análisis de Maquiavelo} se ha hecho tradicionalmente a partir de El principe. Ésta es la obra que ha recibido mayor atención y la que comúnmente se ha considerado su obra fundamental. Sin embargo, debe señalarse que su otra gran obra, los Discursos sobre la primera década de Tito Livio, no desmerece en cuanto a interés y vigor, aunque en términos generales haya recibido siempre una atención mucho menor. Es posible que una de las razones más importantes para atender primordialmente a lo que se dice en El principe y sólo en segundo lugar a lo que contienen los Discursos, sea que en el primero es donde con mayor claridad se puede encontrar lo que la opinión popular concibe como maquiavelismo, es decir, el arte de gobernar o de alcanzar el poder valiéndose de cualquier medio o recurso, sin reparar en ninguna consideración ni escrúpulo. Por el contrario, se ha considerado tradicionalmente que los Discursos tienen como objetivo fundamental aconsejar a los ciudadanos comunes sobre los mejores medios de fundar, gobernar y conservar una república.

Pero esta distinción es cierta sólo parcialmente. El juicio que se ha difundido sobre el primer libro es en términos generales correcto, sin embargo, no puede decirse lo mismo sobre el segundo. Maquiavelo se ocupa en éste fundamentalmente de las repúblicas por cierto, pero

* Departamento de Política y Cultura, UAM-Xochimilco. 
ROBERTO GARCÍA JURADO

realiza también numerosos comentarios sobre el gobierno de los principados y sobre el gobierno general de un Estado, sin distinguir en muchos casos si se refiere a una forma de gobierno u otra. No obstante, el punto de atención central de los Discursos es el examen de la fundación, gobierno y conservación de las repúblicas hecho a partir del análisis de la organización y el desarrollo histórico de la república romana, en cuya labor ocupó un lugar central la obra de Tito Livio.

El análisis del gobierno republicano a partir de la historia de Roma cumplía un doble propósito. El primero y más importante era el de demostrar la utilidad y pertinencia del método histórico. Como es bien sabido, Maquiavelo consideraba que la historia no tenía una tendencia de cambio lineal, una evolución progresiva, sino que se movía en círculos, es decir, se repetía ineludiblemente a través de un desarrollo cíclico. Así, el estudio de las causas, desarrollo y consecuencias de los acontecimientos del pasado brindaban enseñanzas prácticas y permitían formular máximas para cualquier momento de la historia de la humanidad.

La certeza de Maquiavelo sobre su método histórico se debía a que consideraba que la naturaleza humana no había registrado cambio alguno desde los tiempos más remotos de la humanidad, es decir, a pesar de las transformaciones económicas, sociales, políticas y culturales, su esencia se había mantenido intacta. Los hombres responden siempre a los mismos apetitos, pasiones y temores. A partir de esta noción, Maquiavelo pretendía demostrar que el estudio de la estructura y desarrollo de otras repúblicas del pasado, como la romana, permitiría entender mejor lo que acontecía a las repúblicas italianas del siglo XVI.

El otro propósito era menos analítico y más emotivo. Mediante el estudio de la república romana se proponía también evocar su grandeza, destacar el espíritu cívico que animó su construcción y recordar su posición preeminente en Europa. De este modo, lo que Maquiavelo perseguía era alentar a los Estados italianos a recuperar ese pasado grandioso y defenderse del acoso de las potencias europeas, que intervenían en la península itálica con gran facilidad. 
- No obstante, debido a la leyenda negra que pesa sobre Maquiavelo y a estas aspiraciones de alcanzar la unidad italiana, se ha prestado poca atención a su concepto de república. Además, este término ha sido utilizado de maneras tan distintas y ambiguas a lo largo de la historia de la filosofia política, que es muy frecuente observar cómo de sus tantas acepciones no prevalece claramente ninguna: algunas veces se le usó para designar una forma de gobierno, otras como sinónimo de Estado y otras como equivalente de la democracia.

Pero para Maquiavelo la república tiene una significación clara y precisa. En los Discursos se exponen ampliamente las características de esta forma de gobierno, desarrolladas en torno a tres rasgos generales: la constitución republicana, la libertad republicana y la virtud republicana. El análisis a través de estos rasgos permitirá mostrar la riqueza y el vigor de esta parte del pensamiento de Maquiavelo tan poco conocida.

\section{La constitución republicana}

En el mundo antiguo se dio una coincidencia más o menos extendida en la concepción de las diferentes formas de gobierno. En términos generales se aceptaba que podian dividirse en seis tipos. Sin duda alguna la clasificación más difundida fue la de Aristóteles, que las dividía en dos grupos, tres positivas y tres negativas. Las del primer grupo las llamaba monarquía, aristocracia y gobierno constitucional, y las del segundo tiranía, oligarquía y democracia. Con diferentes variantes, esta clasificación perduró hasta el mundo moderno, pero a partir de Maquiavelo adquirió fuerza la idea de una nueva división, que distinguía tan sólo dos formas esenciales, la república y el principado. Cada una de ellas tenía sus correspondientes especies y subespecies, pero en realidad su distinción no resultaba tan determinante, pues lo fundamental seguía siendo la separación de las dos formas fundamentales. ${ }^{1}$

${ }^{1}$ A través del libro de Norberto Bobbio La teoría de las formas de gobierno en la historia del pensamiento político se puede realizar una primera 
Posteriormente, la otra clasificación que dejó huella en la historia del pensamiento político fue la de Montesquieu, quien estableció una clasificación tripartita, distinguiendo república, monarquía y tiranía. No obstante, fue sobre todo a partir de la Revolución francesa y del resto de las revoluciones burguesas europeas que la clasificación de gobiernos se redujo nuevamente a dos tipos. En tanto que en la mayor parte de estas revoluciones no se hacía distinción entre monarquía y tiranía, pues se consideraba que todo gobiemo unipersonal era necesariamente tiránico, se difundió rápidamente la idea de que sólo existían en la realidad dos posibilidades; que el Estado se gobernara como república o como monarquía. Esta última era necesariamente tiránica; representaba los excesos más detestables del poder absoluto, y siempre estaba dispuesta a defender los privilegios y abusos de los antiguos estamentos feudales, a menos que se le sometiera al imperio de la ley y el parlamento, lo que en realidad significaba anular sus facultades gubernamentales tradicionales. En contraste, se atribuía a las repúblicas las características contrarias, esto es, un gobierno moderado y respetuoso de los hombres $y$, sobre todo, fundado en la plena igualdad de todos los integrantes del Estado.

68 De este modo, en el mundo moderno la república representó esencialmente un gobiemo asentado en la igualdad. Las revoluciones burguesas y la sociedad posrevolucionaria enarbolaron la divisa de una sociedad de iguales para contraponerla a la sociedad de desiguales, de privilegios y exenciones del mundo feudal. Era una consigna efectiva para convocar a un amplio espectro de sectores sociales en contra del antiguo régimen, y aunque se trataba obviamente de una igualdad válida sólo en ciertos aspectos, su novedad y las posibilidades que con ella se abrían la hacían muy seductora.

Así, las ideas republicanas se identificaron directamente con las ideas igualitarias: la igualdad social requería necesariamente una forma de gobierno republicana. No obstante, poco a poco, el concepto de

aproximación a este tema, ya que describe de manera general las principales teorías que sobre esta materia se han formulado. 
república fue sustituyéndose por el de democracia, el cual terminó al final suplantándolo de modo absoluto. ${ }^{2}$ Pero en este tránsito se perdió una distinción esencial. La democracia moderna se construyó de manera gradual, comenzando por asegurar un número limitado de derechos individuales y de aspectos sociales en los cuales privasen criterios igualitarios, a lo que siguió un proceso de expansión y ampliación de estas esferas, lo cual condujo a pensar en muchas ocasiones que tal tendencia evolucionaría de una manera incesante, hasta llegar a una sociedad donde privara la igualdad absoluta. Sin embargo, el concepto tradicional de igualdad republicana no era el de la igualdad absoluta, la igualdad asociada a la democracia. Mientras que en ésta no se establecían diferencias substanciales entre los ciudadanos, en la primera tal diferenciación constituía un aspecto esencial de su funcionamiento. ${ }^{3}$

Así, para Maquiavelo la república significaba mucho más que sólo igualdad. La igualdad era un ingrediente importante ciertamente, pero al mismo tiempo la distinción entre los ciudadanos era vital.

Maquiavelo consideraba que lo que distinguía a la república era su régimen de igualdad y libertad, así como la virtud de sus ciudadanos. Para comenzar, examinemos lo que entendía por igualdad. Es necesario destacar que no se trataba de una igualdad simple, aquella que Mosca consideraba vulgar porque igualaba a los hombres hasta en las penas y el sufrimiento. No se trataba pues de una igualdad que estableciera sus parámetros a partir de un criterio numérico, aritmético, que tratara igual a cada ciudadano por tratarse de "uno"; no, para Maquiavelo la república permitía establecer un régimen en donde privara una igualdad compleja, una igualdad que tratara igual a los iguales pero reconociera a los desiguales, atendiera a la diferencia entre el mérito y la mediocridad, distinguiera la virtud del vicio, el vigor de la molicie; se

${ }^{2}$ En Teoría de la democracia, Giovanni Sartori explica cómo se dio el tránsito conceptual entre estos dos modelos; de la república a la democracia.

${ }^{3}$ A través del liberalismo del siglo XIX se conservó la idea de la diferenciación de los ciudadanos, pero poco a poco fue perdiendo fuerza hasta disolverse completamente. Cfr. José Guilherme Merquior, Liberalismo viejo y nuevo, 1988, México, FCE. 
trataba sobre todo de una igualdad geométrica, aquella que concibe que el Estado está formado por distintas partes, cuyas funciones, características y tareas son claramente distintas. ${ }^{4}$

A esto se refiere Maquiavelo cuando habla de una república bien ordenada. No se refiere a que prive una igualdad absoluta entre sus ciudadanos, sino a que las diferentes partes del Estado ocupen el sitio que les corresponde por mérito y función.

Esta concepción orgánica del Estado, donde cada una de sus partes tiene asignadas funciones especificas, parece una noción totalmente rebasada, anacrónica y distante. Rousseau, por ejemplo, no aceptaba la existencia de cuerpos, organizaciones o asociaciones que intermediaran entre la sociedad y el Estado, pues el recuerdo de las corporaciones feudales hacía suponer que cualquier tipo de organización social cristalizaría la desigualdad entre los ciudadanos. Así, la imagen del Estado moderno y particularmente de la democracia se construyó bajo este supuesto, es decir, la creación de una ciudadanía inclusiva e indiferenciada.

No obstante, la transición del Estado feudal al moderno no significó la abolición de las corporaciones sino el tránsito de un tipo de sistema 70. corporativo a otro; de una sociedad estamental a una de organizaciones. El organismo del Estado moderno no posee la estructura del orden estamental medieval, sino la de un pluralismo corporativo extenso y complejo, pero que al igual que su predecesora tiene una lógica y dinámica interna, esencial para la interacción política.

${ }^{4}$ Ludovico Settala lo expresa de este modo: "La verdad es que la igualdad que se debe mantener en la república no es una igualdad aritmética en el sentido de que los cargos y las magistraturas se distribuyan sin tener en cuenta la calidad de las personas; este tipo de igualdad no es favorable a la conservación del Estado, porque no todas las personas son adecuadas para todos los cargos; la igualdad debe ser geométrica, o sea, que los nombramientos y la asignación de los cargos se efectúa considerando la condición y calidad de los ciudadanos. La diferencia entre la república común y la democracia consiste en esto; que en la democracia se aplica la distribución aritmética, y en la otra la geométrica." La razón de Estado, Madrid, FCE, p. 173. 
Sólo la ficción con la que en muchas ocasiones se cubre al Estado moderno permite observarlo como una gran masa de ciudadanos discerniendo y deliberando aisladamente. De ninguna manera podría funcionar así. En todos los Estados modernos se aprecia una extensa red de partidos, organizaciones y asociaciones cuya existencia no es sólo tolerada, sino deseada y requerida, pues, como antaño, tienen funciones estatales específicas. ${ }^{5}$

Siguiendo esa antigua doctrina de la concepción orgánica estatal, Maquiavelo establece que la república está formada por tres partes: el pueblo, los nobles y el príncipe. Reconoce que existen repúblicas dominadas por uno de estos tres elementos, en cuyo caso se trata de repúblicas democráticas, aristocráticas o monárquicas, respectivamente. Pero en caso de que no operen justamente y estén corrompidas, entonces deberán denominarse repúblicas de licencia, oligárquicas o tiránicas, todo esto de acuerdo con los principios que estableció Aristóteles. Sin embargo, Maquiavelo señala que las repúblicas de este tipo tienen una vida efímera; su basamento exclusivo en sólo uno de los componentes las conduce a un acelerado proceso de desgaste y agotamiento. Para remediar tal degeneración, lo que propone es un régimen mixto, que combine lo mejor de la monarquía, la aristocracia y la democracia, de acuerdo a los conceptos de los antiguos, o lo mejor del pueblo, los nobles y el príncipe, para expresarlo en los términos que prefiere Maquiavelo.

${ }^{5}$ La comparación no es sencilla, pues no se acostumbra establecer tal paralelismo entre ambas estructuras. Tal vez existan diferencias entre una y otra que deban advertirse, sin embargo, una consideración detenida puede mostrar similitudes notables. De hecho, si se examinan con este espíritu los siguientes textos, se podrá comprender mejor la idea: Louis Hartz, "Democracia: imagen y realidad", en La democracia en la actualidad, W. Chambers y R. Salisbury (comps.), 1967, México, UTEHA; Robert Dahl, Los dilemas del pluralismo demo-crático, 1991, México, CONACULTA-Alianza editorial; Joseph Shumpeter, Capitalismo, socialismo y demócracia, 1983, Barcelona, Orbis. 
ROBERTO GARCÍA JURADO

El pueblo, el componente más numeroso, ofrece contribuciones negativas y positivas. Comúnmente se ha creído que Maquiavelo lo despreciaba y denigraba sin ninguna consideración. Una gran cantidad de comentaristas y críticos han dado esa imagen distorsionada y parcial, contribuyendo así a oscurecer su teoría. Un libro tan popular como el de Maurice Jolly, Diálogo en el infierno entre Maquiavelo y Montesquieu, puede servir de ejemplo para mostrar con qué desatino se ha interpretado su pensamiento. ${ }^{6}$ Es necesario señalar que, en efecto, en repetidas ocasiones se refiere a la vileza y mediocridad popular, pero en muchas otras se expresa con calificativos igualmente duros del príncipe o de los nobles.

Para Maquiavelo la multitud reunida e informe no tenía ninguna utilidad; sin jefes no servía para nada: nada había más inconsistente, volátil e impredecible que el pueblo reunido. A ese temperamento inconstante es al que deben atribuirse los disturbios y desórdenes característicos de los gobiernos populares, ya que ambicionando la posición, riqueza y prestigio de los mejor colocados, el pueblo no reconocía freno para el desorden, pues cualquier cambio o inestabilidad le favorecería.

72 No obstante, si el pueblo reunido tendía a equivocarse, de manera aislada y en el examen de determinados asuntos particulares no erraba,

${ }^{6}$ En este libro, Jolly llega a poner en boca de Maquiavelo la expresión de ¡Báscula constitucional maravillosa! para referirse así de manera irónica y mordaz a la división de poderes que ha hecho clásica Montesquieu, dando a entender que tal disposición era simplemente un artefacto para disimular las verdaderas intensiones del príncipe, esto es, las de concentrar el poder de manera absoluta. De acuerdo a ello, Maquiavelo no tomaba en serio las posibilidades del gobierno mixto, pues tal como lo presenta Jolly, era sólo una cortina de humo. A este respecto, no hay que perder de vista el tono irónico y jocoso con el que está escrito el libro, por lo que no se le puede tomar con absoluta seriedad, pero también es necesario señalar que ese tipo de nociones sobre él son las que se han difundido con más vigor y las que permiten concluir que nada de lo que decía era franco y sincero, sino envuelto en dobleces y celadas. 
de hecho, podia tener un mejor juicio que los nobles y el príncipe. Maquiavelo dice que en la designación de los funcionarios públicos normalmente el pueblo elegía mejor que el príncipe, es decir, el equipo de gobierno al servicio del monarca podía ser mucho más útil siendo designado democráticamente.

Más aún, en uno de los pasajes que ha sido citado profusamente para acreditar el espíritu republicano de Maquiavelo, éste llega a decir que el gobierno popular es mejor que el real y que es más adaptable y duradero. Explicaba que el gobierno popular es mejor que el real porque si los excesos de la multitud causan desorden, los del príncipe pueden conducir la república a la ruina. Además, un régimen republicano es más flexible que el real porque, si está bien ordenado, tiene la capacidad de que sus partes se adecuen y reajusten más fácilmente entre sí para encontrar un nuevo equilibrio, algo que es muy dificil que logre el príncipe cuando gobierna autocráticamente, pues no es sencillo que cambie el ánimo y disposición de su propio fuero interno. ${ }^{7}$

Sin embargo, ninguna república puede existir sin hombres que sobresalgan y se distingan del resto de los ciudadanos, cuyos atributos excepcionales forman el conjunto de lo que Maquiavelo llama los nobles. No obstante, estos nobles deben destacar por sus propios méritos personales y no por la riqueza o los títulos nobiliarios heredados. No son los títulos los que honran a los hombres, sino los hombres quienes honran a los títulos.

Maquiavelo critica con mordacidad a los hombres que forman parte de los nobles y cuyo único mérito es disfrutar de la riqueza acumulada por sus ancestros, lo que les permite vivir de la especulación y en la más absoluta improductividad. Para comprender mejor esta descalificación debe considerarse que Maquiavelo observaba el comportamiento de las oligarquías italianas de entonces, cuya especulación comercial

${ }^{7} \mathrm{El}$ mismo Isaiah Berlin pierde de vista la distinción que hace Maquiavelo entre república y principado, ya que generaliza diciendo que su pensamiento se caracteriza por proponer la centralización incondicional del poder político. Cfr. "La originalidad de Maquiavelo", en Contra la corriente, 1983, México, FCE. 
y financiera no sólo corrompía las costumbres en el interior de las repúblicas, sino que además les generaba innumerables problemas en sus relaciones con el exterior. ${ }^{8}$

Pero la función equilibrante de los nobles era insustituible. Su capacidad para fungir como ejemplo y modelo para el resto de los ciudadanos constituye el motor más vigoroso de la vida republicana. Además, su función militar es imprescindible, pues son los jefes y conductores de la milicia republicana, ya que sin su mando el ejército se convierte en una masa informe.

El príncipe, paradójicamente, es la pieza central del equilibrio republicano. Mientras el resto de las partes de la república se encuentre sano y en su posición correspondiente, el príncipe podrá cumplir satisfactoriamente esta responsabilidad, pero cuando no sea así, se corromperá aceleradamente; ante la ausencia de frenos externos no reconoce ningún límite y se convierte entonces en el propulsor de la ruina de la república. Maquiavelo lanza una sentencia inapelable: son muy pocos los príncipes buenos y sabios. A la inversa de Filmer, quien diría que son pocos los reyes malvados y muchos los bondadosos, Maquiavelo señalaba que el príncipe podía hacer bien a la república bajo la vigilancia y celo de los demás componentes. ${ }^{9}$

El príncipe está llamado a fundar, conservar y nutrir a la república. Para Maquiavelo la única manera de fundar una república bien ordenada es que su constitución sea obra de un solo hombre, de un príncipe fundador, arquitecto maestro del edificio constitucional. Una de las mayores aportaciones del príncipe se encuentra en su contribución

${ }^{8}$ No sería prudente estigmatizar bajo esta sola sentencia a la oligarquía de la época. Su función en la actividad económica y social en el Renacimiento es bastante compleja. Sin embargo, sí puede apreciarse cómo Maquiavelo critica consistentemente este tipo de comportamientos de amplios sectores oligárquicos. Cfr. Alfred von Martin, Sociología del renacimiento, 1995, México, FCE.

${ }^{9}$ En contra de la opinión más difundida, Maquiavelo no era un defensor a ultranza de la monarquía y el poder absoluto; como hubo tantos antes y después de él, cuyos ejemplos típicos son Bodino, Hobbes y Filmer. 
MAQUIAVELO

legislativa fundacional; en dar unas leyes tan apropiadas que no haya necesidad de transformarlas a pesar del transcurso temporal, de los ajustes dentro de la estructura interna de la república y de las mudanzas del escenario internacional. Maquiavelo acude sin vacilación al ejemplo puesto por Licurgo en Esparta, no menciona la Atenas de Solón, quizás porque admirara profundamente la vocación guerrera de los espartanos, pero, en todo caso, no vacila al afirmar que ésa es la única manera de diseñar una república bien ordenada.

Pero el príncipe tiene también una importante función en la vida cotidiana de la república. Su posición equilibrante es evidente si se observa que en las disputas y controversias que se suscitan en la república en torno a los asuntos públicos sólo existen dos partidos; el de los nobles y el del pueblo. El príncipe no entra en la disputa; para que no se desgarre la república y se respete cierto estatuto en la lucha, el príncipe debe mantenerse fuera, vigilante, imparcial.

Ésta es la fisonomía de una república bien ordenada. En ella el respeto a la ley, la observancia de las buenas costumbres y la noción correcta de la posición que ocupa cada uno es indispensable. De aquí puede deducirse lo infundado de una enorme cantidad de comentaristas que han atribuido a Maquiavelo la intención de fundar siempre un poder absoluto, tiránico y malévolo. ${ }^{10}$ En muchas partes Maquiavelo hace alusión a la utilidad de gobernar un Estado mediante una u otra forma de gobierno, señala, por ejemplo, que ahí donde las costumbres se han corrompido, las leyes quebrantado, las multitudes desbordado y los magnates sublevado, no hay otra manera de gobernar que fundando un reino, es decir, a través del poder absoluto, un poder que tenga la fuerza para doblegar cualquier resistencia, cualquier desorden y cualquier tentativa de suplantación. Por el contrario, donde exista

${ }^{10}$ El pequeño texto de Louis Gautier-Vignal, Maquiavelo, 1993, México, FCE, es una muestra de la incomprensión hacia el florentino, dado que no penetra en el pensamiento de Maquiavelo sino que se sitúa fuera, desde donde lo critica y descalifica. Por ejemplo, hacia el final sugiere una conexión entre Maquiavelo y el totalitarismo, lo que es en verdad insostenible. 
ROBERTO GARCÍA JURADO

una república bien ordenada, no sólo es imposible el poder centralizador absoluto sino inútil; las otras dos partes de la república, los nobles y el pueblo, conociendo su posición y disfrutando de los honores y beneficios que les corresponden nunca intentarán suplantar al príncipe ni alterar el orden para defenderse; el príncipe les conferirá lo que merecen. En un régimen de este tipo a ningún partido convendrá un cambio de gobierno, al contrario, se guardarán de conservar el que tienen, en vista de lo cual el príncipe no temerá por su posición ni tendrá necesidad de recurrir a acciones tiránicas para conservarla.

Maquiavelo admiraba la constitución de la república de Venecia. De hecho, ejemplificaba con ella el ordenamiento correcto de la república, ya que en ese Estado el pueblo, los nobles y el príncipe tenían la posición que les correspondía a través del Consiglio Grande, el Senado y el Dux. La prueba de su correcto orden radicaba precisamente en su durabilidad, el cual se había mantenido casi intacto desde mediados del siglo XIII, y que le valió el nombre de república serenísima. ${ }^{11}$

Esta consistente estabilidad de los Estados es lo que Maquiavelo consideraba uno de los fines explícitos más importantes de su correcto ordenamiento interior. Al igual que Aristóteles, asumía que la estabi76 lidad política era en sí misma un valor; nada había más dañino que el desorden, el desgobierno y la anarquía. Por esta razón, cuando se trataba de la conservación del Estado, en muchas ocasiones llegó a justificar excepcionales medidas violentas, ilegales u opresivas. ${ }^{12}$ En el

${ }^{11}$ Cfr. Federico Chabod, Escritos sobre el Renacimiento, 1990, México, FCE.

${ }^{12}$ En el texto citado, Berlin considera que para los teóricos de la razón de Estado las acciones reprobables son excepcionales, en tanto que para Maquiavelo son normales. Pero Maquiavelo mismo es quien se encarga de desmentir tal idea: "Ningún hombre sabio censurará el empleo de algún procedimiento extraordinario para fundar un reino u organizar una república; pero conviene al fundador que cuando el hecho lo acuse, el resultado lo excuse; y si esto es bueno, como sucedió con Rómulo, siempre se le absolverá. Digna de censura es la violencia que destruye, no la violencia que reconstruye. Debe, sin embargo, el legislador ser prudente y virtuuso para no dejar como herencia a otro la autoridad de que se apoderó, porque, siendo 
caso de la república, la fórmula de su conservación se encontraba en la invariabilidad de su constitución, el respeto a la ley y el castigo para sus infractores. Ésa era la única forma de mantener el esquema de convivencia entre las distintas partes de la república, que garantizaba la plena igualdad ciudadana, y que era también la condición indispensable para el ejercicio de su libertad.

\section{La libertad republicana}

Los dos principios constitutivos que caracterizan a la república son la igualdad y la libertad. La igualdad debe ser un sistema complejo de derechos, facultades y obligaciones, así como un mecanismo de sanciones y recompensas, recriminaciones y reconocimientos, es decir, la igualdad republicana no puede ser una igualdad democrática, insensible ante la diferencia y la diversidad. Del mismo modo, la libertad republicana es un conjunto de instituciones y prácticas que permiten la vida independiente del Estado, la autonomía de las partes integrantes de la república y la integridad irrestricta de cada ciudadano, es decir, la libertad republicana no puede ser una licencia desbordada que no reconozca límites, contenciones y responsabilidades.

A lo largo de los Discursos Maquiavelo no deja de insistir en que la libertad republicana debe concebirse tanto como una libertad ante el exterior frente al dominio de potencias extranjeras, como una libertad en el interior del Estado, que permita a cada ciudadano hacer valer sus derechos ante cualquier instancia. ${ }^{13}$ Pero lo más importante es que no las concibe de manera separada, es decir, que pueda disfrutarse de una y carecerse de la otra, para él deben existir juntas, ya que una condilos hombres más inclinados al mal que al bien podría el sucesor emplear por ambición los medios a que él apeló por virtud." Discursos sobre la primera década de Tito Livio, 1971, La Habana, Editorial de ciencias sociales.

${ }^{13}$ Esta concepción dicotómica de la libertad es una de las características de los humanistas cívicos del siglo XV. Cfr. Quentin. Skinner, Los fundamentos del pensamiento político moderno, 1993, México, FCE. 
ROBERTO GARCÍA JURADO

ciona a la otra: una república sin libertad exterior implica que una potencia extranjera domina al Estado, tanto en su conjunto como a cada uno de los ciudadanos de manera individual; de igual manera, una república sin. libertad interior se corrompe automáticamente, se arruina de forma irremediable y pierde su fortaleza. En estas condiciones, no es capaz de defenderse y sucumbe sin ofrecer resistencia ante el más débil asedio exterior. ${ }^{14}$

Para Maquiavelo tampoco es posible establecer una distinción en el interior de la república entre libertad privada y política, al estilo de Benjamin Constant, que atribuía una a los modernos y la otra a los antiguos sin posibilidad de fusión. Maquiavelo concibe que la libertad republicana está compuesta de ambas y no es posible separarlas. Una de las funciones inexcusables de la autoridad pública es sancionar cualquier conducta de los individuos que afecte intereses, posesiones o patrimonio de otros. Así, plantea que ninguna república puede tolerar que se viole la ley sin que haya la correspondiente sanción: la impunidad corroe las bases de la amistad cívica de forma irreparable. Llega a decir que los ciudadanos pueden tolerar el abuso de una autoridad pública legítima, pero nunca el que proviene de una entidad privada. La mejor manera de interpretar esto no es considerando que justifica el abuso del Estado sino señalando el daño que causa al orden civil el no respetar los espacios de la libertad privada. A tal punto se considera reprobable el abuso del Estado, que Maquiavelo insiste en que ninguna constitución republicana puede carecer de las vías lega-

${ }^{14}$ James Burham también ha señalado esta conexión entre libertad interior y exterior, así como su mutua dependencia. Explica que en la construcción de los países europeos se había seguido el camino de la centralización monárquica, por lo que Italia debía hacer lo mismo si deseaba existir: "Si en estos otros países la monarquía había sido el camino necesario para construir la nación, esa forma de gobierno, según indicó Maquiavelo, era todavía más necesaria en Italia, porque en ese país las divisiones políticas eran más acentuadas." Los maquiavelistas: defensores de la libertad, 1945, Buenos Aires, Emecé. 
les apropiadas para que los ciudadanos se defiendan de las acciones públicas. ${ }^{15}$

No obstante, en la preservación de la libertad interior cada parte de la república constituía una amenaza distinta, y al mismo tiempo un factor de conservación. Maquiavelo consideraba que el pueblo era el componente más tentado por los excesos: servía con sumisión y humildad o dominaba con insolencia y opresión. Los ciudadanos en multitud no solamente perdían la capacidad del juicio detenido y meditado, sino también la mutua confianza y fácilmente actuaban guiados por el temor y la angustia. ${ }^{16}$ En contraparte, debido a que la libertad es sobre todo una costumbre, una forma de vivir, el sujeto depositario de ella es precisamente el pueblo, quien dentro del Estado practica y conserva las costumbres y tradiciones, y por la misma razón quien más enérgica y violentamente protesta cuando se pretende pasar sobre ellas. Así, para hablar de libertad, debe dirigirse la atención al tipo de costumbres de un pueblo.

Sin embargo, no era fácil elegir a quién debía encomendarse la guardia de la libertad: al príncipe, a los nobles o al pueblo. Maquiavelo escogió a los nobles, quizá porque encarnaban el conjunto de libertades dentro de una república, las cuales permiten que sus hombres más ilustres se destaquen del resto, se conviertan en sus modelos y guías y, así, doten de vigor y fuerza a las instituciones públicas. ${ }^{17}$ No obstante,

${ }^{15}$ El clásico ensayo de Benjamin Constant La libertad de los antiguos comparada con la de los modernos ha sido una de las bases sobre la que se ha pretendido establecer una separación absoluta entre la libertad privada y la política. No obstante, Maquiavelo muestra que, al menos par él, no existe tal separación.

${ }^{16}$ Los juicios de Maquiavelo sobre la veleidad e inconstancia de la multitud han permitido alimentar su fama despótica y malvada, si bien no presentan gran diferencia con los de teóricos de la sociedad de masas del presente siglo, como José Ortega y Gasset y Karl Mannheim, sobre quienes no ha caído la misma reputación.

${ }^{17}$ Aunque Maquiavelo explícitamente se declaró en favor de un gobierno mixto que combinara lo mejor de la monarquía, la aristocracia y la democra- 
ROBERTO GARCÍA JURADO

tampoco podía entregárseles sin condiciones, dado que su ambición podía rebasar su mesura, advirtiendo que la libertad era deseada por distintos motivos en uno y otro bando: mientras los nobles, siendo pocos, deseaban libertad para mandar, el pueblo sólo la deseaba para vivir seguro.

El príncipe representaba una amenaza para la libertad siempre que actuara sin obedecer a la ley y sin la contención de los nobles y el pueblo. De hecho, Maquiavelo advertía sobre los riesgos de lo que posteriormente fue llamado cesarismo. Este peligro podía sobrevenir cuando los nobles y el pueblo se preocupaban más por defender sus propios intereses que por preservar una legislación de libertades, en cuyo caso ambos se empecinaban en encumbrar a un ciudadano con la sola finalidad de vencer a su adversario, asumiendo el riesgo de que se subordinara a ambas partes emprendiendo el camino más directo hacia la tiranía.

Pero la libertad de la república tiene otra de sus bases en el mismo príncipe, que en el interior obliga a que se viva conforme a la ley que protege la libertad y en el exterior defiende la libertad de la república frente a otros Estados. Maquiavelo sale al paso de las criticas a las

80 facultades extraordinarias que en situaciones de emergencia eran conferidas al príncipe que debilitarían la libertad interior preparando para su extinción, argumentando que tales facultades eran necesarias, pues el mecanismo cotidiano que seguían las repúblicas para decidir acerca de los asuntos públicos era demasiado lento, lo cual las podía volver impotentes en una situación de emergencia. Por tal motivo, todas las constituciones republicanas debían prever dichos recursos e incorporarlos a sus disposiciones constitucionales, ya que si estas facultades extraordinarias se ejercían conforme a la ley nada había que temer.

La libertad exterior de la república preocupaba a Maquiavelo no menos que la interior. De hecho, tradicionalmente se ha considerado que el espíritu cívico y nacionalista fue el que lo llevó a escribir el

cia, una lectura atenta de los Discursos podría sugerir que tal vez se inclinara con mayor preferencia hacia una república aristocrática. 
MAQUIAVELO

capítulo final de El principe, donde el espíritu analítico y prescriptivo es sustituido por la arenga y el fervor patrio. Sin embargo, tal ánimo también se encuentra en varios pasajes de los Discursos, en los cuales lamenta la desunión y debilidad de los Estado italianos.

Su concepción misma de la formación de los Estados se funda en esta preocupación por la libertad exterior: la formación de las ciudades se realizaba por dos caminos; por la colonización de extranjeros o por la reunión de los hombres procedentes de comarcas pequeñas que se reunían en una mayor para defenderse mejor de los extranjeros. Así, la libertad, el progreso, la pervivencia y el bienestar de una ciudad dependían directamente de su libertad exterior.

En cierto sentido, puede aceptarse que la arenga de Maquiavelo para construir la unidad italiana se debía en parte a su espíritu patriótico, pero habría que conceder igual atención a su insistencia sobre la necesidad de disfrutar de la libertad exterior para que el Estado progresara. Esto adquiere un sentido mucho más profundo si se sitúa a Italia en la competencia comercial y económica que ya por entonces se manifestaba descarnadamente entre los reinos europeos, dentro de los cuales llevaban la delantera aquellos que con su unidad nacional habían construido su mercado interior y consolidado sus mercados exteriores.

Si en muchos otros aspectos Maquiavelo criticaba acremente a Francia y España, en éste los admiraba: reconocía que eran pueblos unidos bajo un mismo mando político, lo que les daba enormes ventajas en las pugnas intereuropeas. En este sentido, se ha llegado a decir que lo que le preocupaba no era propiamente la unidad italiana sino su defensa frente a las potencias externas, el sacudimiento de la injerencia extranjera en la vida interior de cada Estado italiano. Pero para él estaba claro que no podía conseguirse una cosa sin la otra. ${ }^{18}$

${ }^{18}$ Federico Chabod ha señalado una serie de inconsistencias de apreciación histórica en las tesis de Maquiavelo, por ejemplo, que resultaba un tanto anacrónica su propuesta de unificar Italia bajo el mando de un príncipe, cuando en el resto de los Estados europeos se había iniciado un movimiento de restricción hacia los monarcas. Asimismo, que otro error radicaba en 
La indefensión italiana producida por su desintegración fue la que lo hizo lamentar y criticar la función de la iglesia católica en la península: nunca había sido lo suficientemente fuerte como para unificar a Italia ni lo suficientemente débil como para permitir que otro Estado lo hiciera. A partir se esa actitud se ha difundido la idea de que Maquiavelo despreciaba y denigraba la religión, sobre todo la cristiana. Si bien criticó con gran severidad las costumbres de la iglesia católica de la época, la cual apartándose de las tradiciones originales del cristianismo había conducido a esa religión a una serie de prácticas pervertidas y corruptas, nunca desestimó la importancia de la religión. Tanto en El principe como en los Discursos se puede observar que otorga una importante función social a la religión, por medio de la cual pueden alimentarse las buenas costumbres cívicas del pueblo. ${ }^{19}$

No obstante, pocas décadas después de la muerte de Maquiavelo, en la lejana Inglaterra Christopher Marlowe comenzaba a difundir su supuesto desprecio hacia la religión, haciendo que en El judio de Malta, recite un opúsculo donde se burla y la desprecia mordazmente, con lo cual continuaba difundiéndose su fama con rasgos impíos y perversos.

Maquiavelo es tan insistente sobre la libertad exterior de las repúbli82 cas que, contemplando el ejemplo de la romana, afirma que su indepen-

descartar a los ejércitos mercenarios para apoyarse en las milicias propias, cuando en el resto de los Estados europeos se había iniciado también un proceso de construcción de ejércitos permanentes y pagados. No obstante, estas críticas dan pie a una polémica más profunda sobre las circunstancias históricas de Italia y Europa. Cfr., Escritos sobre Maquiavelo, 1994, México, FCE.

${ }^{19} \mathrm{El}$ fraile Tomás Campanella, uno de los más furibundos críticos de Maquiavelo, era una clara muestra de la corrupción a la que había llegado la iglesia católica. No sólo concebía métodos tan brutales como el florentino, pues aconsejaba al rey de España que para vencer la resistencia de los flamencos los echara simplemente de su propio territorio, sino que ni siquiera sentía el patriotismo de aquél, pues soñaba con la dominación de todos los Estados por un nuevo imperio cristiano depositado en la monarquía española. Cfr., La política, 1991, Madrid, Alianza. 
dencia no puede garantizarse más que con el expansionismo. No es posible seguir el modelo independiente de Esparta y Venecia. Dada la situación internacional de competencia y expansión, no pueden vivir independientes, mucho menos si son pequeñas, pues para preservarse deberán extenderse. Ni siquiera es posible un punto medio. Para Maquiavelo, las repúblicas no son necesariamente pacíficas -como después pensaría Kant-; para conservarse deben atacar y defenderse, y, en consecuencia, perfeccionar una economía de guerra, lo que evitará que sus campañas bélicas las lleven a la ruina. Como Roma, deben financiar la guerra con el botín que de ella obtienen, y para conservar sus posesiones sin incurrir en el costoso sostenimiento de ejércitos de ocupación, deben fundar colonias que permitan controlar esas posesiones.

En este aspecto, debe reconocerse la clara comprensión del funcionamiento interestatal por parte de Maquiavelo, al observar que los Estados renacentistas no eran autárquicos ni estaban aislados sino parte de un sistema, cuya dinámica se alimentaba precisamente de la existencia de otras unidades políticas en permanente tensión internacional. Así pues, no era posible imaginar un Estado viviendo pacífica y felizmente, pues para sobrevivir estaba obligado a permanecer en alerta, no permitir que los demás le adelantaran en la competencia ni perder la iniciativa en la conquista de nuevos territorios. ${ }^{20}$

Para preservar la libertad había que practicar la guerra, de donde se desprende la enorme importancia que le concede en todos sus escritos, haciendo derivar incluso la libertad de la república de la propia organización del ejército.

En este sentido, una de sus recomendaciones más comunes en $E l$ príncipe como en los Discursos es que tanto la república como el prin-

${ }^{20} \mathrm{El}$ nacimiento del Estado-nación moderno es incomprensible sin el sistema de Estados que lo circunda. La disputa y competencia entre estas unidades políticas son inmanentes a su fundación y, de hecho, la permanente tensión que existe entre ellos es precisamente la manera en que permanecen unidos en el sistema internacional. Cfr., Paul Kennedy, Auge y caida de las grandes potencias, 1994, Barcelona, Plaza y Janés. 
ROBERTO GARCÍA JURADO

cipado deben disponer de un ejército propio, pues la experiencia le había enseñado que nada había más peligroso que confiar la defensa a mercenarios -requisito que después se convertiría en componente característico del Estado moderno. Pero además señala la importancia de su composición, pues indica que tanto por razones de estrategia militar como por sus implicaciones sociales, la infantería debía ocupar un puesto relevante, pues no sólo simbolizaba la disposición de la república a defender su libertad, sino que también encarnaba la determinación del ciudadano armado de manifestar su libertad y defender su patria por propio convencimiento, lo cual era una de las mayores virtudes.

\section{La virtud republicana}

Para definir la naturaleza humana se han configurado tres posiciones fundamentales a lo largo de la historia de la filosofía política. Una que consiste en suponer que el hombre es malo, egoísta y envidioso por naturaleza; otra que lo concibe bueno, generoso y fraternal congénitamente; y la tercera que sostiene que no existe una naturaleza definida sino dependiente del tipo de sociedad, civilización y orden político en el cual se desarrolle cada ser humano. Existen matices, pues los sostenedores de la primera y segunda opinión consideran que tal naturaleza puede atemperarse por la tercera, pero éstas son las tres posibilidades básicas.

Maquiavelo es partidario de la primera. La envidia y la maldad son naturales en el hombre, no puede despojarse de ellas en ningún momento y bajo ninguna circunstancia. Los seres humanos sólo pueden hacer el bien si se les obliga, si existe un conductor que les imponga esa conducta, les ofrezca su ejemplo y les enseñe a obrar correctamente, pero ante su ausencia seguramente volverán a ser malvados. Pero existe otra posibilidad. Pueden adquirir la costumbre de comportarse correctamente de manera duradera a través de la ley, convirtiendo la buena conducta en uno de sus hábitos. Ésta es la idea que permite 
atemperar la sentencia drástica de Maquiavelo, no obstante siempre consideró que el hombre sólo puede hacer el bien por coerción externa.

Este juicio contundente tiene el propósito de advertir a los gobernantes y legisladores, sobre todo a quien pretenda fundar un Estado. Las leyes deben prever que los hombres tienen un apetito ilimitado por todo cuanto los rodea, que no se contienen ante la idea de que no todo pueden tenerlo, y que harán cuanto esté en su mano para conseguirlo. $\mathrm{Su}$ avaricia los hace valorar mucho más los bienes que los honores, pues la aspiración a estos últimos es privilegio de unos cuantos.

Uno de los temas característicos en los escritos de Maquiavelo es el de la virtud. Habla de la virtud del príncipe, de la virtud de los nobles y de la virtud de los ciudadanos. Todas comparten rasgos, pero también se distinguen por diferencias notables.

La virtud del príncipe es ampliamente tratada tanto en el libro que dedica a este personaje como en los Discursos. Su definición es bastante compleja, pues un príncipe puede ser virtuoso en el bien y en el mal, en la perversidad y en la generosidad. Su conducta no puede someterse a una descripción que se convierta en prescripción, puesto que eso precisamente es lo que define su virtud; actuar de acuerdo con las costumbres compartidas y aceptadas por todos los ciudadanos, pero al mismo tiempo saberse apartar de ellas cuando sea necesario. Esto significa que existen situaciones en las cuales la conducta del príncipe puede ser excepcional; no acostumbrada por el resto de los ciudadanos, ni siquiera por él mismo. Éste es, sin duda, uno de los problemas más complejos de la ética política de ahora y de siempre, y es también una de las cuestiones más inquietantes que abordó Maquiavelo y que siempre será su privilegio haber tratado de dilucidar.

El problema es complejo porque a partir de él se separan dos campos de valoración distinta: el de la ética política y el de la ética privada. Y aquí comienzan las dificultades, pues una de las nociones más difundidas en la sociedad burguesa es que no existe esta diferenciación sino sólo la ética privada, a la que debe sujetarse el individuo tanto en la escena privada como en la política. 
ROBERTO GARCIA JURADO

Esta valoración ética se basa en los principios del mundo burgués: el progreso personal como generador de la mejora colectiva, el cumplimiento estricto del contrato comercial, y la acumulación de riqueza como medio de reconocimiento social. A estas líneas generales de conducta debe atenerse el buen ciudadano burgués, esto es, a cultivar los valores de la convivencia privada. Por ello, quien se aparte de este modelo sacrificará sin duda estos principios éticos, sobre todo si se abandona la vida privada para dedicarse a la política, en la cual no sólo se vive apartado de estos valores, sino que prácticamente se renuncia a ellos.

Con lo cual se desprende automáticamente la conclusión de que la política es naturalmente sucia y malévola, y para dedicarse a ella se requiere ser cínico, perverso y traidor. No basta ser amoral, sino que debe estarse dispuesto a ser inmoral. Así, se establecen entonces dos espacios claramente definidos: el de los asuntos públicos, es decir, la política, en el que se mueven aquellos hombres corruptos, malvados y tramposos, y el de los asuntos privados, en donde permanecen los hombres industriosos y honestos. ${ }^{21}$

Por supuesto, nada más irreal. La maldad del Shylock de Shakespeare es tan grande como la de Claudio, y la avaricia del Barrabás de Marlowe es tanta como la perversidad de Tamerlán. La moralidad burguesa ha condenado a quienes se dedican a los asuntos públicos y exonerado a los que sólo se ocupan de los negocios privados, sin embargo, en ninguno de los dos campos se mantiene la pureza moral de manera automática. El individuo dedicado a los asuntos privados puede ser tan

${ }^{21}$ Por el contrario, no es la vida privada sino la pública la que forma el carácter del ciudadano: "Puede decirse que las virtudes y los vicios humanos se definen primariamente en términos políticos. La sociedad civil y sus leyes definen lo que es bueno y lo que es malo y la educación de la sociedad civil forma a los ciudadanos. El carácter de la vida de ésta está decisivamente influido por el carácter del régimen en el cual vive el hombre, y es el régimen lo que alienta o desalienta el crecimiento de los varios tipos humanos." Alan Bloom, Gigantes y enanos, 1991, Buenos Aires, Gedisa. 
MAQUTAVELO

corrupto como el que se ocupa de los públicos, ambos pueden incurrir en faltas igualmente reprobables. ${ }^{22}$

De la misma manera, tampoco es cierto que en la vida privada los individuos cumplan siempre con su deber, de acuerdo con estrictos preceptos morales. Las situaciones excepcionales en las que los individuos tienen que deliberar y elegir ante una disyuntiva moral se presentan tanto en la vida pública como en la privada, en esto no hay diferencia entre uno y otro espacio.

No obstante existen diferencias según el nivel de la responsabilidad. Cuando un individuo decide, su elección afectará sus intereses y, en diferente medida, la situación de quienes se encuentran a su alrededor. Pero la decisión de un hombre público afectará a todo el conjunto de los ciudadanos; sus crímenes y hazañas repercutirán más intensamente.

Este mayor nivel de repercusión es precisamente lo que hace distinta la falta moral en uno y otro campo, pues de acuerdo con Maquiavelo las faltas del príncipe y del hombre público en general, podrán ser disculpadas más razonablemente que las del privado, atendiendo precisamente a esa responsabilidad mayor. No obstante, este argumento no puede utilizarse para justificar los excesos y despotismo del príncipe, pues es ahí donde radica su virtud, en ser capaz de incurrir en faltas morales sólo en atención al bien común, no al suyo propio. ${ }^{23}$

La virtud de los nobles no radica en las mismas actividades de gobierno del príncipe. En muchos casos comparten tareas públicas, pero nunca puede equipararse el nivel de responsabilidad. La virtud de los

${ }^{22}$ José Luis Aranguren señala que para la ética liberal la virtud social es el resultado de las virtudes privadas, cuyo egoísmo, individualismo, industriosidad y honradez comercial producirían la armonía social. Cfr., Etica y política, 1987, Barcelona, Orbis.

${ }^{23}$ Bernard Williams comenta que se requiere el tipo de político para el que existan ciertas cosas moralmente reprobables, -es decir, que conserve un criterio ético, que le permita discernir entre lo correcto y lo incorrectoya que sólo éste podrá aplicar frenos a su conducta. Cfr., "La política y el carácter moral", en Moral pública y privada, Stuart Hampshire (comp.), 1983, México, FCE. 
nobles consiste en destacar de entre el resto de los ciudadanos por medios honorables. Antes que su propio enriquecimiento y opulencia, deben perseguir el honor y reconocimiento de los demás.

Esto es algo poco común entre los hombres debido a que la mayoria prefiere las riquezas y comodidades. No es frecuente que arriesguen su persona, propiedades y familia en aras de una gloria incierta $y$ veleidosa.

Allí radica la virtud noble, en destacar por sus mejores dotes y aceptando el peligro que ello implica, pues ciertamente los nobles disfrutan de una privilegiada posición social, pero también de un riesgo mayor para alcanzarla y sostenerse en ella.

Maquiavelo escribió en una época donde la ética aristocrática estaba siendo suplantada por otra democrática y burguesa. ${ }^{24}$ De ahí que distinga distintas virtudes en cada uno de los componentes del Estado y sentencie sin vacilación que una república requiere ineludiblemente de los nobles, de un conjunto de hombres que destaquen y pongan ejemplo a los demás, pero no en el medio privado sino en el público. A diferencia del principio burgués que por entonces comenzaba a difundirse, considera que el progreso y avance de la república depende no de la persecución del bien privado sino del común, aún cuando ello implique sacrificar algunos intereses individuales. Esto, la búsqueda del bien común, es precisamente lo que distingue a la república como forma de gobierno.

La virtud del ciudadano común es probablemente lo que menos trata Maquiavelo, aunque no necesariamente lo que menos le preocupa. Varios historiadores han explicado que en aquella época se escribieron una gran cantidad de libros de consejos para monarcas, nobles y cortesanos, debido a que muchas repúblicas estaban siendo eliminadas y absorbidas por reinos y principados, lo que hacía que el interés de

${ }^{24}$ No sólo se estaba pasando de una ética aristocrática a una democrática, sino que en esa naciente sociedad burguesa el aire se iba enrareciendo para los héroes y el honor aristocrático. Cfr. Herman Nohl, Introducción a la ética, 1993, México, FCE. 
los escritores no fuera el de dirigirse al típico ciudadano republicano, ya en extinción, sino a los nacientes monarcas. Uno de los ejemplos más típicos de estos textos es El cortesano de Castiglione, desde su aparición convertido en clásico. Sin embargo, difícilmente podría explicarse su éxito atendiendo sólo a este fenómeno, y mucho menos podrían comprenderse los Discursos.

Maquiavelo no se ocupa de una manera extensa de la virtud del ciudadano, pero algunas indicaciones al respecto enmarcan toda su concepción de la república. En primer lugar, señala que el ciudadano virtuoso es aquel comprometido con la defensa de su patria; ésa es su mayor virtud. Tanto los nobles como el príncipe deben estar dispuestos a ello, pero si tal determinación está ausente en el ciudadano común no hay esperanzas: nada pueden hacer los comandantes sin un ejército comprometido con la defensa de la patria. En cambio, un pueblo determinado en su defensa pero sin comandantes comprometidos, puede hacer surgir de entre sus filas a aquellos que por su carácter más noble y habilidad guerrera puedan ponerse al frente y conducirlo.

Por otro lado, Maquiavelo es un exponente típico del hombre renacentista, ese ser que todo lo sabe, lo puede, y se compromete con ello. La virtud del ciudadano no es producto de la naturaleza sino del empeño, radica también en ser responsable y forjador de su destino, su suerte y su modo de vida. Su mérito es mayor -considerando que por naturaleza no es virtuoso- es sobreponerse a su propia naturaleza y habituarse a obrar correctamente.

En El príncipe Maquiavelo había dado un gran paso al afirmar que podía conceder que la Fortuna determinara en gran parte la vida del hombre, tal vez en la mitad, pero en los Discursos va mucho más allá y llega a decir que alli donde hay orden y disciplina rara vez falta la Fortuna, es decir, que ésta ya no es tan responsable del acontecer humano, sino que ahora le corresponde tan sólo una posición marginal, accesoria.

Para Maquiavelo la república es igualdad, libertad, virtud. Los Discursos están animados por un entusiasta espíritu republicano, es cierto, pero eso no obsta para reconocer limitaciones de esta forma de go- 


\section{ROBERTO GARCÍA JURADO}

bierno. En El príncipe está igualmente presente la admiración hacia la figura del monarca y las instituciones de la monarquía. Pero ninguna contradicción hay en ello. Para Maquiavelo se trata de dos recursos al servicio del hombre para ordenar su convivencia política. 